(2) OPEN ACCESS

Queens Hospital Center, Medicine, Mount Sinai Medical Center, Queens, New York, USA

\section{Correspondence to} Dr Theo Trandafirescu, Queens Hospital Center, Medicine, Mount Sinai Medical Center, Queens, NYC 11432, USA; ttrandaf@gmail.com

Accepted 6 February 2020 Published Online First 1 April 2020

\title{
Clinical update on pulmonary hypertension
}

\author{
Salim Yaghi, Anastasia Novikov, Theo Trandafirescu
}

\begin{abstract}
Pulmonary hypertension (PH) is a chronic, complex and challenging disease. Advances in treatment are for the subset of patients with pulmonary arterial hypertension. Selected review of the literature was conducted incorporating the European Society of Cardiology/European Respiratory Society 2015 guidelines and recommendations from the Sixth World Symposium on Pulmonary Hypertension. $\mathrm{PH}$ is classified into five groups based on WHO classification. Echocardiography remains the initial test of choice, and careful assessment of the right system aids in the diagnosis and prognosis of the disease. Right heart catheterization remains the gold standard of diagnosis and key guidance of treatment. Multidisciplinary approach is recommended for the care of patients with $\mathrm{PH}$. Treatment selection is based on individual risk stratification of patients, and early referral to specialized PH centers improves outcomes of patients. Treating PH is complex and is best carried out in PH centers and with multidisciplinary approach. Early diagnosis and referral to those centers are key not to delay treatment.
\end{abstract}

\section{INTRODUCTION}

Pulmonary hypertension (PH) has remained a challenging chronic progressive disease since the First World Symposium meeting in 1973, which opened the era to groundbreaking discoveries about its pathophysiology and various treatment options. In this review, we try to summarize the latest evidence about the disease, its definition, classification, diagnosis and treatment, focusing mainly on group 1 pulmonary arterial hypertension $(\mathrm{PAH})$.

\section{Definitions}

Pulmonary hypertension is defined as a mean pulmonary arterial pressure (mPAP) greater than $20 \mathrm{~mm} \mathrm{Hg}$ at rest as per the Sixth World Symposium on Pulmonary Hypertension in $2018,{ }^{1}$ and greater than $25 \mathrm{~mm} \mathrm{Hg}$ at rest as per the guidelines issued by the European Society of Cardiology (ESC)/European Respiratory Society (ERS) in $2015 .^{2}$ A subset of patients with pulmonary arterial pressure (PAP) of between 21 and $24 \mathrm{~mm} \mathrm{Hg}$ are considered highrisk patients with possible poor outcomes if left unfollowed, which is why they were included in the Sixth World Symposium definition. ${ }^{1}$

The authors based this recommendation on the fact that the original definition of mPAP of at least $25 \mathrm{~mm} \mathrm{Hg}$ was chosen somewhat arbitrarily and does not represent the upper limit of normal mPAP in the general population. ${ }^{23}$

The prior assessment of PAP at exercise is not recommended with the current definitions due to lack of reliable data that precisely define which levels of exercise-induced changes in PAP or pulmonary vascular resistance have prognostic implications. ${ }^{23}$

Hemodynamic definitions of $\mathrm{PH}$ which include more than just the PAP during right heart catheterization (RHC) are probably more useful clinically as they have prognostic and therapeutic implications and can help with further classification of the disease. The major players here are pulmonary vascular resistance and pulmonary capillary wedge pressure (table 1). ${ }^{1-3}$

\section{Classifications}

The WHO classification ${ }^{12}$ categorizes multiple clinical conditions into five groups according to similarities in clinical presentation, pathological findings, hemodynamic characteristics and treatment approach. These subtypes of $\mathrm{PH}$ are agreed on by the ESC in 2016 and the Sixth World Symposium (box 1 and tables 2-4).

\section{Diagnosis}

ECG findings

An ECG may provide supportive evidence of $\mathrm{PH}$, but a normal ECG does not exclude the diagnosis. ${ }^{4}$ An abnormal ECG is more likely in severe rather than mild PH. ECG abnormalities may include $\mathrm{P}$ pulmonale, right axis deviation, RV hypertrophy, RV strain, right bundle branch block, and QTc prolongation. Prolongation of the QRS complex and QTc suggests severe disease. $^{4}$

Supraventricular arrhythmias may occur in advanced disease, in particular atrial flutter, but also atrial fibrillation, with a cumulative incidence of $25 \%$ in patients after 5 years. ${ }^{5}$ Ventricular arrhythmias are rare.

\section{Echocardiography}

Echocardiography remains the first test of choice when PH is suspected, ${ }^{6}$ not only because it estimates systolic PAP but also because it can assess for signs of right ventricular (RV) dysfunction as well as left ventricular (LV) dysfunction.

Reading and interpreting echocardiographic imaging in respect to $\mathrm{PH}$ and its related effects on the right cardiac side is challenging; 


\begin{tabular}{llll}
\hline $\begin{array}{l}\text { Table } 1 \\
\text { types }\end{array}$ & Hemodynamicdefinitions of pulmonary hypertension \\
\hline $\begin{array}{l}\text { Definition } \\
\text { Mean pulmonary artery }\end{array}$ & $\begin{array}{l}\text { Pulmonary capillary } \\
\text { wedge pressure (mm Hg) }\end{array}$ & $\begin{array}{l}\text { Pulmonary vascular } \\
\text { resistance (Wood units) }\end{array}$ \\
\hline $\begin{array}{l}\text { solated precapillary PH } \\
\text { (formerly yulmonary } \\
\text { arterial hypertension) }\end{array}$ & 20 & $<15$ & 3 \\
$\begin{array}{l}\text { Combined postcapillary } \\
\text { and precapilary pulmonary } \\
\text { hypertension (PH) } \\
\text { Isolated postcapillary PH }\end{array}$ & 15 & 3 \\
\hline
\end{tabular}

therefore, the ESC guidelines issued a probability score for $\mathrm{PH}$ based on echocardiographic features.

The ESC/ERS and the Sixth World Symposium do not recommend using estimated systolic PAP anymore given inaccuracies of right atrial pressure (RAP) estimation and the amplification of measurement errors using derived variables; thus, continuous-wave Doppler measurement of peak tricuspid regurgitation velocity (TRV) is the main variable for assigning echocardiographic probability of $\mathrm{PH}^{1} 289$ (tables 5 and 6).

The algorithm in figure 1 summarizes how to use echocardiography and the probability score for $\mathrm{PH}$ to determine further testing and whether RHC for definitive diagnosis is indicated. It can be said that patients with symptoms plus intermediate or high echocardiographic probability score should go for RHC, and only asymptomatic patients with high probability should go for RHC; otherwise, follow-up with repeat echocardiography is reasonable (figure 1 ).

\section{Cardiac MRI}

Cardiac MRI (CMR) is accurate and reproducible in the assessment of RV size, morphology and function, and allows non-invasive assessment of blood flow, including stroke volume, cardiac output (CO), pulmonary arterial distensibility and RV mass. ${ }^{10}$

In patients with suspected $\mathrm{PH}$, the presence of late gadolinium enhancement, reduced pulmonary arterial distensibility and retrograde flow has high predictive value in the identification of $\mathrm{PH}$; however, no single CMR measurement can exclude $\mathrm{PH} .{ }^{2}$ In patients with $\mathrm{PH}, \mathrm{CMR}$ may also be useful in cases with suspected congenital heart disease if echocardiography is not conclusive.

Contrast-enhanced and unenhanced magnetic resonance angiography has potential in the study of the pulmonary vasculature in patients with suspected chronic thromboembolic $\mathrm{PH}$, particularly in clinical scenarios such as suspected chronic embolism in pregnant women, young patients or when iodine-based contrast media injection is contraindicated. $^{2} 10$

CMR provides useful prognostic information for patients with PAH both at baseline and at follow-up. ${ }^{2} 10$

\section{Severity and prognosis of disease}

There is no single variable that provides sufficient diagnostic and prognostic value for patients with $\mathrm{PH}^{11}{ }^{12}$; therefore, a comprehensive assessment of multiple variables at regular intervals is strongly recommended by the ESC to be done in expert PH centers. This complex assessment is used to define patients' status and classify
Box 1 Updated clinical classification of pulmonary hypertension (PH)

1. Pulmonary arterial hypertension (PAH).

- Idiopathic.

- Heritable.

- Drug-induced and toxin-induced (see table 2).

- Associated with the following:

- Connective tissue disease.

- Portal hypertension.

- Congenital heart disease.

- Schistosomiasis.

- PAH long-term responders to calcium channel blockers (see table 3).

- PAH with overt features of pulmonary veno-occlusive disease/or pulmonary capillary hemangiomatosis (see table 4).

- Persistent PH of the newborn syndrome.

2. Pulmonary hypertension due to left heart disease.

- PH due to heart failure with preserved left ventricular ejection fraction.

- PH due to heart failure with reduced left ventricular ejection fraction.

- Valvular heart disease.

- Congenital/acquired cardiovascular conditions leading to postcapillary PH.

3. Pulmonary hypertension due to lung disease and/ or hypoxia.

- Obstructive pulmonary diseases.

- Restrictive pulmonary diseases.

- Other lung disease with mixed restrictive/obstructive pattern.

- Hypoxia without lung disease.

- Developmental lung disorders.

4. Pulmonary hypertension due to pulmonary artery obstruction.

- Chronic thromboembolic PH.

- Other pulmonary artery obstructions.

- Sarcoma (high or intermediate grade) or angiosarcoma.

- Other malignant tumors (renal, uterine, germ cell tumor of the testis, other tumors).

- Non-malignant tumors (uterine leiomyoma).

- Arteritis without connective tissue disease.

- Congenital pulmonary arteries stenoses.

- Parasites (hydatidosis).

5.Pulmonary hypertension with unclear and/or multifactorial mechanisms.

- Hematological disorders: chronic hemolytic anemia and myeloproliferative disorders.

- Systemic and metabolic disorders: pulmonary Langerhans cell histiocytosis, Gaucher disease, glycogen storage disease, neurofibromatosis and sarcoidosis.

- Others: fibrosing mediastinitis, chronic renal failure (with/without dialysis), pulmonary tumorous thrombotic microangiopathy and HIV.

them into low, intermediate or high risk. ${ }^{2}$ Most of the proposed variables and cut-off values are based on expert opinion. 
Table 2 Classification of drugs and toxins associated with pulmonary arterial hypertension

\begin{tabular}{ll}
\hline Definite & Possible \\
\hline Aminorex & Cocaine \\
\hline Fenfluramine & Phenylpropanolamine \\
\hline Dexfenfluramine & L-tryptophan \\
\hline Benfluorex & St John's wort \\
\hline Methamphetamines & Amphetamines \\
\hline Dasatinib & Interferon alpha and beta \\
\hline Toxic rapeseed oil & Alkylating agents \\
& Bosutinib \\
\hline & Direct-acting antiviral agents against hepatitis C virus \\
& Leflunomide \\
\hline & Indirubin (Chinese herb Qing-Dai) \\
\hline
\end{tabular}

Table 3 Definitions of acute and long-term response

Acute pulmonary vasoreactivity Reduction of $\mathrm{mPAP}>10 \mathrm{~mm} \mathrm{Hg}$ to reach an for patients with idiopathic, absolute value of $\mathrm{mPAP}<40 \mathrm{~mm} \mathrm{Hg}$. heritable or drug-induced PAH.

Increased or unchanged cardiac output.

Long-term response to CCBs. New York Heart Association functional class I/II.

With sustained hemodynamic improvement (same or better than achieved in the acute test) after at least 1 year on CCBs only.

CCBs, calcium channel blockers; mPAP, mean pulmonary arterial pressure; $\mathrm{PAH}$, pulmonary arterial hypertension.

Table 4 Signs suggestive of venous and capillary (pulmonary veno-occlusive disease/pulmonary capillary hemangiomatosis) involvement

\begin{tabular}{|c|c|c|}
\hline \multicolumn{2}{|l|}{ Pulmonary function tests } & $\begin{array}{l}\text { Decreased DLCO }(<50 \%) \text {. } \\
\text { Severe hypoxemia. }\end{array}$ \\
\hline \multicolumn{2}{|l|}{ High-resolution chest CT } & $\begin{array}{l}\text { Septal lines, centrilobular ground } \\
\text { glass opacities, and mediastinal } \\
\text { lymphadenopathy. }\end{array}$ \\
\hline \multicolumn{2}{|l|}{ Response to PAH therapy } & Possible pulmonary edema. \\
\hline Genetic background & & Biallelic EIF2AK4 mutations. \\
\hline \multicolumn{2}{|l|}{ Occupational exposure } & Organic solvent (trichloroethylene). \\
\hline \multicolumn{3}{|c|}{$\begin{array}{l}\text { DLCO, diffusing capacity of the lungs for carbon monoxide; PAH, pulmonary } \\
\text { arterial hypertension. }\end{array}$} \\
\hline \multicolumn{3}{|c|}{$\begin{array}{l}\text { Table } 5 \text { Echocardiographic probability of pulmonary } \\
\text { hypertension }(\mathrm{PH}) \text { in symptomatic patients with suspicion of } \\
\text { pulmonary hypertension }\end{array}$} \\
\hline $\begin{array}{l}\text { Peak tricuspid } \\
\text { regurgitation } \\
\text { velocity }(\mathrm{m} / \mathrm{s})\end{array}$ & $\begin{array}{l}\text { Presence of other } \\
\text { echocardiographic } \\
\text { signs of PH }\end{array}$ & $\begin{array}{l}\text { Echocardiographic } \\
\text { probability of pulmonary } \\
\text { hypertension }\end{array}$ \\
\hline$<2.8$ or not measurable & No & Low \\
\hline$<2.8$ or not measurable & Yes & Intermediate \\
\hline $2.9-3.4$ & No & \\
\hline $2.9-3.4$ & Yes & High \\
\hline$>3.4$ & Not required & \\
\hline
\end{tabular}

Table 6 Echocardiographic signs of PH

\begin{tabular}{|c|c|c|}
\hline A. Ventricles & B. Pulmonary artery & $\begin{array}{l}\text { C. Inferior vena cava } \\
\text { and right atrium }\end{array}$ \\
\hline $\begin{array}{l}\text { Right ventricle/left } \\
\text { ventricle basal diameter } \\
\text { ratio }>1.0 \text {. }\end{array}$ & $\begin{array}{l}\text { Right ventricular } \\
\text { outflow Doppler } \\
\text { acceleration time } \\
<105 \text { ms and/or mid- } \\
\text { systolic notching. }\end{array}$ & $\begin{array}{l}\text { Inferior vena cava } \\
\text { diameter }>21 \mathrm{~mm} \text { with } \\
\text { decreased inspiratory } \\
\text { collapse ( }<50 \% \text { with } \\
\text { inspiration). }\end{array}$ \\
\hline \multirow[t]{2}{*}{$\begin{array}{l}\text { Flattening of } \\
\text { interventricular septum } \\
\text { (left ventricular } \\
\text { eccentricity index }>1.1 \text { in } \\
\text { systole and/or diastole). }\end{array}$} & $\begin{array}{l}\text { Early diastolic } \\
\text { pulmonary regurgitation } \\
\text { velocity }>2.2 \mathrm{~m} / \mathrm{s} \text {. }\end{array}$ & $\begin{array}{l}\text { Right atrial area (end- } \\
\text { systole) }>18 \mathrm{~cm}^{2} \text {. }\end{array}$ \\
\hline & $\begin{array}{l}\text { Pulmonary artery } \\
\text { diameter }>25 \mathrm{~mm} \text {. }\end{array}$ & \\
\hline
\end{tabular}

At least two from different categories $(A, B$ or $C$ ) should be present to alter the probability of echocardiographic $\mathrm{PH}$ score.

$\mathrm{PH}$, pulmonary hypertension.

Mortality numbers are crude rates that were studied in patients with idiopathic PAH (IPAH) only; therefore, individualization of assessment is needed. The individual risk is modified by other factors, such as the rate of disease progression and the presence or absence of signs of right heart failure, or syncope, and also by the presence of comorbidities, age, sex, background therapy, and PAH subtype, among others (table 7).

An important note to take from these variables is that functional class and exercise capacity are vital in the assessment process. The WHO Functional Class (WHO-FC) remains one of the most powerful predictors of survival, and 6 min walking test remains the most widely used exercise test in PH centers (table 8). ${ }^{1211-13}$

We can note as well that RV function is a key determinant of exercise capacity, and in contrast to common belief the estimated systolic PAP at rest is usually not prognostic and not relevant for therapeutic decision making. ${ }^{214}$ It is reasonable to say that the effects of this high pressure, especially on the right cardiac system, determine exercise capacity and predict survival.

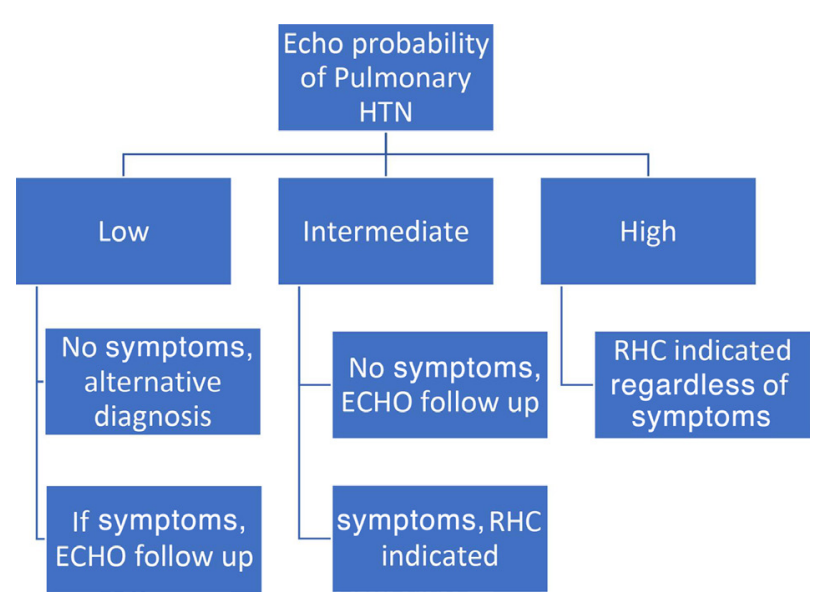

Figure 1 ECHO probability score diagnostic algorithm 


\begin{tabular}{|c|c|c|c|}
\hline $\begin{array}{l}\text { 1-year mortality } \\
\text { prognosis factors }\end{array}$ & Low risk $(<5 \%)$ & $\begin{array}{l}\text { Intermediate risk } \\
(5 \%-10 \%)\end{array}$ & High risk (>10\%) \\
\hline $\begin{array}{l}\text { Clinical right heart } \\
\text { failure }\end{array}$ & Absent & Absent & Present \\
\hline Symptom progression & No & Slow & Rapid \\
\hline Syncope & No & $\begin{array}{l}\text { Occasional syncope } \\
\text { with heavy exercise or } \\
\text { orthostatic change }\end{array}$ & $\begin{array}{l}\text { Repeated syncope, } \\
\text { especially at rest }\end{array}$ \\
\hline WHO Functional Class & I and III & III & IV \\
\hline $6 \mathrm{MWD}(\mathrm{m})$ & 440 & $165-440$ & $<165$ \\
\hline $\begin{array}{l}\text { Cardiopulmonary } \\
\text { exercise testing }\end{array}$ & $\begin{array}{l}\text { Peak } \mathrm{VO}_{2}>15 \mathrm{~mL} / \mathrm{min} / \mathrm{kg} \\
(>65 \% \text { pred) } \\
\text { VE } / \mathrm{VCO}_{2} \text { slope }<36\end{array}$ & $\begin{array}{l}\text { Peak VO }{ }_{2} 11-15 \mathrm{~mL} / \mathrm{min} / \\
\mathrm{kg}(35 \%-65 \% \mathrm{pred}) \\
\text { VE } / \mathrm{VCO}_{2} \text { slope } 36-44.9\end{array}$ & $\begin{array}{l}\text { Peak } \mathrm{VO}_{2}<11 \mathrm{~mL} / \mathrm{min} / \mathrm{kg} \\
(<35 \% \text { pred) } \\
\mathrm{VE} / \mathrm{VCO}_{2} \text { slope }>45\end{array}$ \\
\hline NT-proBNP (ng/L) & $<300$ & $300-1400$ & 1400 \\
\hline $\begin{array}{l}\text { Imaging } \\
\text { (echocardiography } \\
\text { and/or cardiac MRI) }\end{array}$ & $\begin{array}{l}\text { RA area }<18 \mathrm{~cm}^{2} \\
\text { No pericardial effusion }\end{array}$ & $\begin{array}{l}\text { RA area } 18-26 \mathrm{~cm}^{2} \\
\text { Minimal pericardial } \\
\text { effusion }\end{array}$ & $\begin{array}{l}\text { RA area }>26 \mathrm{~cm}^{2} \\
\text { Pericardial effusion }\end{array}$ \\
\hline Hemodynamics & $\begin{array}{l}\mathrm{RAP}<8 \mathrm{~mm} \mathrm{Hg} \\
\mathrm{Cl}>2.5 \mathrm{~L} / \mathrm{min} / \mathrm{m}^{2} \\
\mathrm{SvO}_{2}>65 \%\end{array}$ & $\begin{array}{l}\text { RAP } 8-14 \mathrm{~mm} \mathrm{Hg} \\
\text { CI } 2.0-2.4 \mathrm{~L} / \mathrm{min} / \mathrm{m}^{2} \\
\mathrm{SvO}_{2} 60 \%-65 \%\end{array}$ & $\begin{array}{l}\mathrm{RAP}>14 \mathrm{~mm} \mathrm{Hg} \\
\mathrm{Cl}<2.0 \mathrm{Lmin} / \mathrm{m}^{2} \\
\mathrm{SvO}_{2}<60 \%\end{array}$ \\
\hline
\end{tabular}

\section{Treatment and management of PH Historical background}

Despite PH being recognized as early as 1891 by German physician Ernst von Romberg, ${ }^{15}$ it took nearly 100 years for the first disease-specific medication intravenous epoprostenol to be approved in $1995 .{ }^{1516} \mathrm{PH}$ remains an orphan disease that has received little clinical attention possibly due to lack of solid scientific understanding, and even after the introduction of right heart catheterization by Werner Forssmann in 1929 and direct measurement of PAP no drugs have been available for chronic treatment. It was not until the appetite-suppressant, aminorex-induced $\mathrm{PAH}$ epidemic in 1973 when WHO held its first meeting in Geneva to assess what is known and not known about $\mathrm{PH}$ and PAH. ${ }^{15} 16$ After this, significant interest from the scientific community rapidly ensued, with advances in the understanding of the mechanisms involved in the pathophysiology and biology of PAH and IPAH and with clinical trials being conducted in the 1980s and early 1990s.

In 1982, the first treatment for primary PH was published in the form of heart-lung transplantation by Norm Shumway and colleagues. ${ }^{17}$ The first medical therapy was not realized until the Nobel Prize winning work on prostacyclin by Vane, Bergstrom and Samuelson. Even after demonstrating the beneficial effects of intravenous prostacyclin in 1982, 13 years have passed before epoprostenol was finally approved by the Food and Drug Administration (FDA) in 1995 for the treatment of IPAH (formerly known as primary pulmonary hypertension).

Bosentan, an endothelin ETA/ETB receptor antagonist, was the first oral therapy approved for the treatment of PAH.

\begin{tabular}{ll}
\hline Table 8 & WHO functional classes \\
\hline $\begin{array}{l}\text { WHO Functional } \\
\text { Class }\end{array}$ & Description \\
\hline Class I & $\begin{array}{l}\text { Can perform ordinary physical activity without symptoms. } \\
\text { Class II }\end{array}$ \\
$\begin{array}{l}\text { Ordinary activity causes symptoms of dyspnea, fatigue, chest pain or near syncope. } \\
\text { Comfortable at rest. }\end{array}$ \\
\hline $\begin{array}{l}\text { Class III } \\
\text { Class IV }\end{array}$ & $\begin{array}{l}\text { Comfortable at rest. } \\
\text { Cannot perform any activity without symptoms. Dyspnea and/or fatigue at rest. }\end{array}$ \\
\hline
\end{tabular}

\section{Evolution of PAH therapy}

Epoprostenol intravenously (Flolan): approved in 1995.

- Bosentan orally: approved in 2001.

- Treprostinil subcutaneously: approved in 2002.

- lloprost inhaled: approved in 2004.

- Treprostinil intravenously: approved in 2005.

- Sildenafil orally: approved in 2005.

- Ambrisentan orally: approved in 2007.

- Tadalafil orally: approved in 2009.

- Treprostinil inhaled: approved in 2009.

- Epoprostenol intravenously (Veletri): approved in 2010.

- Riociguat orally: approved in 2013.

- Macitentan orally: approved in 2013.

- Treprostinil orally: approved in 2013.

- Selexipag orally: approved in 2015.

With advances in biological, molecular and genetic medicine, we now have 14 FDA drugs for PAH.

Treatment of WHO group 1 PAH by targeting the nitric oxide, endothelin and prostaglandin pathways has been standard since the 2003 World Symposium on Pulmonary Hypertension (WSPH) guidelines. In the following lines and algorithms, we try to summarize the treatments proposed by the the Sixth WSPH task force and the ESC 2018 guidelines.

General measures and supportive therapy should be initiated to all patients with confirmed diagnosis of PAH.

\section{General measures}

- Avoid pregnancy.

- Influenza and pneumococcal vaccines.

- Psychosocial support.

- Supervised exercise training and avoid excessive physical activity that leads to distressing symptoms.

- Inflight oxygen $\left(\mathrm{O}_{2}\right)$ therapy for partial pressure of oxygen $\left(\mathrm{PO}_{2}\right)$ less than $60 \mathrm{~mm} \mathrm{Hg}$ or class III-IV.

- Avoid general anesthesia and use epidural instead, if feasible.

\section{Supportive therapy}

Diuretics for RV failure and fluid overload.

Long-term $\mathrm{O}_{2}$ if $\mathrm{PO}_{2}$ is consistently less than $60 \mathrm{~mm} \mathrm{Hg}$.

Consider oral anticoagulant for IPAH and heritable PAH (no strong evidence to support low therapeutic range warfarin therapy that targets international normalized ratio (INR) $1.5-2.5$ ). ${ }^{18} 19$

Correct anemia and/or iron deficiency.

Use of ACE, angiotensin receptor blockers (ARBs), beta blockers (BB) and ivabradine is not recommended in PAH unless there is a compelling indication.

All patients with a diagnosis of group $1 \mathrm{PAH}$ according to WHO should be referred to a $\mathrm{PH}$ center to guide treatment and ongoing management.

Intravenous epoprostenol received the strongest recommendation for therapy in high-risk patients due to its proven mortality benefit in patients with $\mathrm{PAH}$ even as a monotherapy. ${ }^{20}$

Vasoreactivity testing is indicated in patients with IPAH, heritable pulmonary arterial hypertension $(\mathrm{HPAH})$ and 
PAH due to toxins or drugs. Vasoactive patients should be treated with high doses of CCB (diltiazem, nifedipine or amlodipine) and reassessed in 3-4 months. If no adequate response, then patients can be treated like non-vasoactive patients.

Calcium channel blockers (CCBs). It has been increasingly recognized that only a small number of patients with IPAH who demonstrate favorable response to acute vasodilator testing at the time of RHC do well with CCBs. ${ }^{1} 21$ The CCBs that have been predominantly used in reported studies are nifedipine, diltiazem and amlodipine, with particular emphasis on nifedipine and diltiazem. The choice of CCB is based on the patient's heart rate at baseline, with a relative bradycardia favoring nifedipine and amlodipine and a relative tachycardia favoring diltiazem. The daily doses of these drugs that have shown efficacy in IPAH are relatively high: $120-240 \mathrm{mg}$ for nifedipine, $240-720 \mathrm{mg}$ for diltiazem and up $20 \mathrm{mg}$ for amlodipine. Factors that limit dose increase are usually systemic hypotension and lower limb peripheral edema. Patients with IPAH who meet the criteria for a positive vasodilator response and are treated with CCBs should be followed closely both for safety and efficacy, with a complete reassessment after 3-4 months of therapy including RHC. If the patient does not show an adequate response, defined as being in WHO-FC I or II and with a marked hemodynamic improvement (near normalization), additional PAH therapy should be instituted. In some cases the combination of CCB with the approved PAH drugs is required due to further clinical deterioration in case of CCB withdrawal attempts.

Vasodilator responsiveness does not appear to predict a favorable long-term response to CCB therapy in patients with $\mathrm{PAH}$ in the setting of connective tissue disease (CTD), HIV, portopulmonary hypertension and pulmonary venoocclusive disease.

Patients who have not undergone a vasoreactivity study or those with a negative study and at low or intermediate risk should not be started on CCBs due to potential severe side effects (eg, hypotension, syncope and RV failure), and can be treated with either disease-specific monotherapy or oral combination therapy.

No data for any specific monotherapy over the other, so choice is individualized.

Monotherapy from any class based on suitability has been relegated a 'residual role' in the following patients ${ }^{1}$ :

1. Vasoreactive patients with $\mathrm{PH}$ who maintain reactivity and functional class I/II with sustained hemodynamic improvement after at least 1 year on CCBs only.

2. Patients with a low-risk profile who have historically been stable on monotherapy.

3. Patients with IPAH more than 75 years old with multiple risk factors for left heart disease.

4. Patients with PAH with suspicion or high probability of pulmonary veno-occlusive disease or pulmonary capillary hemangiomatosis.

5. Patients with PAH associated with HIV, portopulmonary hypertension, or uncorrected congenital heart disease, as they were not included in randomized controlled trials of upfront combination therapy.

6. Patients with very mild disease defined on the basis of WHO-FC I, pulmonary vascular resistance of 3-4 Wood units (WU), mPAP of less than $30 \mathrm{~mm} \mathrm{Hg}$, and normal right ventricle on echocardiography.
7. Combination therapy unavailable or contraindicated.

In non-vasoactive and high-risk patients, combination therapy including intravenous prostacyclin analog, especially intravenous epoprostenol (decreases 3-month mortality in high-risk patients), is recommended. ${ }^{20}$

In case of inadequate clinical response to initial combination or monotherapy, sequential double or triple combination therapy is recommended (riociguat and phosphodiesterase type 5 inhibitor (PDE-5i) are contraindicated).

In case of inadequate clinical response with sequential double combination therapy, triple combination should be attempted.

Refer to lung transplant if there is inadequate response to combination therapy. Balloon atrial septostomy (decompresses the right heart chambers by creating interatrial right to left shunt; this will improve LV preload and CO, and also improve systemic $\mathrm{O}_{2}$ transport despite arterial $\mathrm{O}_{2}$ desaturation) should be considered as palliative or bridging procedure in patients who are deteriorating despite maximal medical therapy.

The following dual combination therapies are recommended on the basis of evidence:

1. Macitentan and sildenafil.

2. Riociguat and bosentan.

3. Selexipag and endothelin receptor antagonist or PDE$5 \mathrm{i}$, or both.

Endothelin receptor antagonists (ERA). Activation of the endothelin system has been demonstrated in both plasma and lung tissue of patients with PAH. Endothelin-1 exerts vasoconstrictor and mitogenic effects by binding to two distinct receptor isoforms in the pulmonary vascular smooth muscle cells, endothelin receptors types A and B.

Ambrisentan. Ambrisentan is an ERA that preferentially binds with endothelin receptor type A. The incidence of abnormal liver function tests ranges from $0.8 \%$ to $3 \%$. Monthly liver function assessment is not mandated in the USA. An increased incidence of peripheral edema has been reported with ambrisentan use.

Bosentan. Bosentan is an oral active dual endothelin receptor type $A$ and $B$ antagonist and the first molecule of its class to be synthesized. Increases in hepatic aminotransferases occurred in approximately 10\% of patients and were found to be dose-dependent and reversible after dose reduction or discontinuation. For these reasons, liver function testing should be performed monthly in patients receiving bosentan.

Macitentan. Dual ERA macitentan has shown benefits to both patients who had not received treatment previously and those receiving additional therapy for PAH. While no liver toxicity was shown, reduction in blood hemoglobin $\leq 8 \mathrm{~g} / \mathrm{dL}$ was observed in $4.3 \%$ of patients receiving $10 \mathrm{mg}$ of macitentan.

\section{PDE-5i and guanylate cyclase stimulators}

Inhibition of the cyclic guanosine monophosphate (cGMP) degrading the phosphodiesterase type 5 enzyme results in vasodilation through the nitic oxide (NO)/cGMP pathway at sites expressing this enzyme. Since the pulmonary vasculature contains substantial amounts of phosphodiesterase type 5, the potential clinical benefit of PDE-5is has been 
investigated in PAH. In addition, PDE-5is exert antiproliferative effects. All three PDE-5is approved for the treatment of erectile dysfunction-sildenafil, tadalafil and vardenafil—cause significant pulmonary vasodilation, with maximum effects observed after 60, 75-90 and 40-45 min, respectively.

\section{Sildenafil}

Sildenafil is an orally active, potent and selective inhibitor of phosphodiesterase type 5. Most side effects of sildenafil are mild to moderate and mainly related to vasodilation (headache, flushing, epistaxis).

Based on pharmacokinetic data, an intravenous formulation of sildenafil has been proposed as a bridge for patients with $\mathrm{PAH}$ on long-term oral treatment who are temporarily unable to ingest tablets.

\section{Tadalafil}

Tadalafil is a once-daily dispensed selective PDE-5i. The side effect profile is similar to that of sildenafil.

\section{Vardenafil}

Vardenafil is a twice-daily dispensed PDE-5i. The side effect profile is similar to that of sildenafil.

\section{Riociguat}

While PDE-5is such as sildenafil, tadalafil and vardenafil enhance the NO/cGMP pathway, slowing cGMP degradation, soluble guanylate cyclase (sGC) stimulators enhance cGMP production. Moreover, preclinical studies show sGC stimulators have antiproliferative and antiremodeling properties in various animal models. The most common serious adverse event was syncope. The combination of riociguat and PDE-5i is contraindicated due to hypotension.

Prostacyclin analogs and prostacyclin receptor agonists Prostacyclin is produced predominantly by endothelial cells and induces potent vasodilation of all vascular beds. This compound is the most potent endogenous inhibitor of platelet aggregation and also appears to have both cytoprotective and antiproliferative activities. Dysregulation of the prostacyclin metabolic pathways has been shown in patients with PAH as assessed by a reduction of prostacyclin synthase expression in the pulmonary arteries and of prostacyclin urinary metabolites. The clinical use of prostacyclin in patients with $\mathrm{PAH}$ has been extended by the synthesis of stable analogs that possess different pharmacokinetic properties but share qualitatively similar pharmacodynamic effects.

\section{Epoprostenol}

Epoprostenol (synthetic prostacyclin) has a short half-life (3-5 min) and is stable at room temperature for only 8 hours; it requires cooling and continuous administration by means of an infusion pump and a permanent tunneled catheter. Epoprostenol improves symptoms, exercise capacity and hemodynamics and is the only treatment shown to reduce mortality. Treatment with epoprostenol is initiated at a dose of $2-4 \mathrm{ng} / \mathrm{kg} / \mathrm{min}$, with doses increasing at a rate limited by side effects (flushing, headache, diarrhea, leg pain). The optimal dose varies between individual patients, ranging in the majority between 20 and $40 \mathrm{ng} / \mathrm{kg} / \mathrm{min}$. Serious adverse events related to the delivery system include pump malfunction, local site infection, catheter obstruction and sepsis. Guidelines for the prevention of central venous catheter

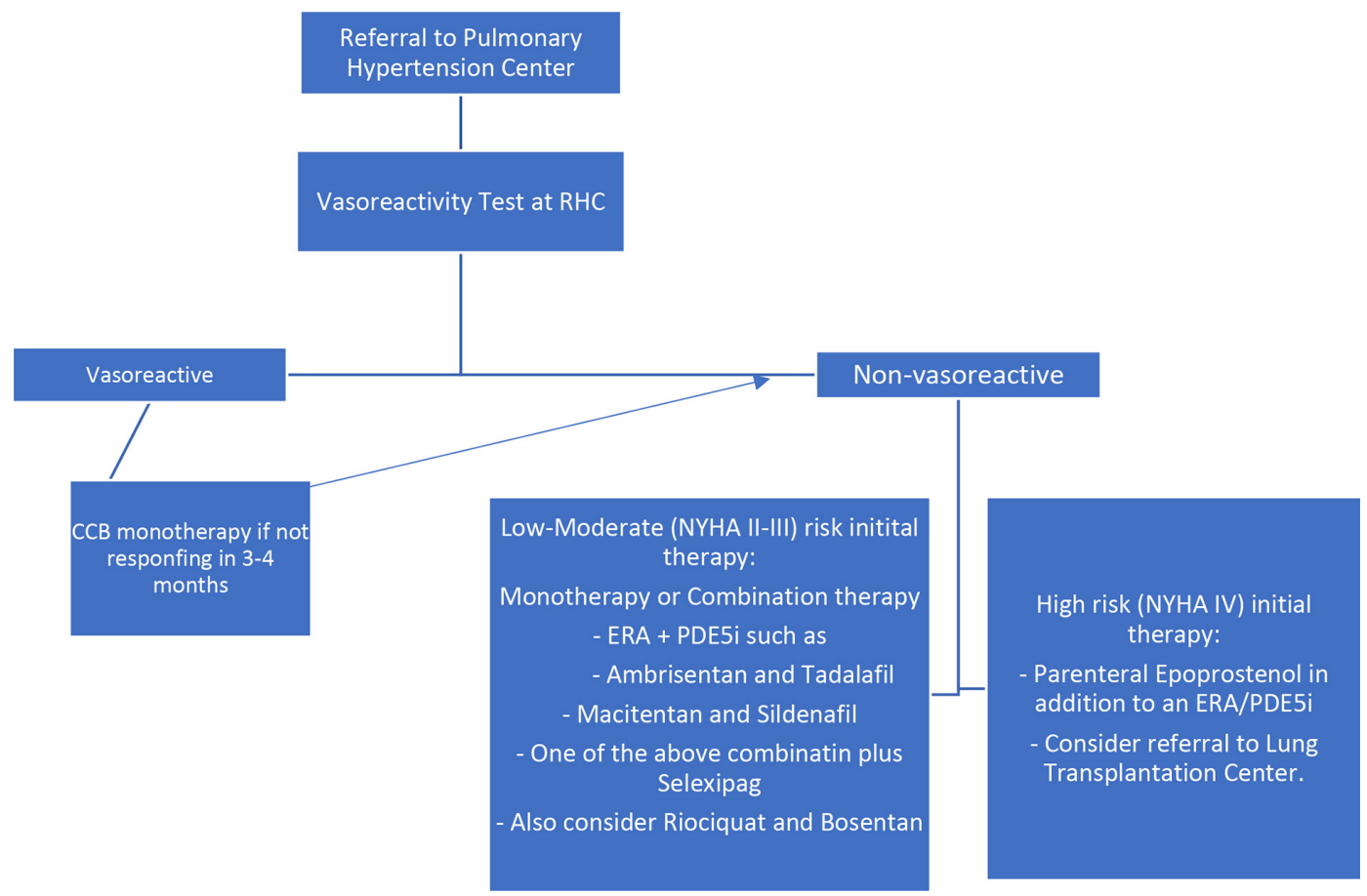

Figure 2 RHC, right heart catheterization; CCB, calcium channel blockers; NYHA, New York Heart Association; ERA, endothelin receptor antagonists; PDE5, phosphodiesterase type 5 inhibitor. 
bloodstream infections have been proposed. Abrupt interruption of the epoprostenol infusion should be avoided because in some patients this may lead to a $\mathrm{PH}$ rebound with symptomatic deterioration and even death.

\section{Iloprost}

Iloprost is a chemically stable prostacyclin analog available for intravenous, oral or aerosol administration. The effects of oral iloprost have not been assessed in PAH.

\section{Treprostinil}

Treprostinil is a tricyclic benzidine analog of epoprostenol, with sufficient chemical stability to be administered at ambient temperature. These characteristics allow administration of the compound by intravenous and subcutaneous routes. The subcutaneous administration of treprostinil can be accomplished by a microinfusion pump and a small subcutaneous catheter. Infusion site pain is the most common adverse effect of treprostinil, leading to discontinuation of treatment in $8 \%$ of cases on active drug and limiting dose increases in an additional proportion of patients. Treatment with subcutaneous treprostinil is initiated at a dose of $1-2 \mathrm{ng} / \mathrm{kg} / \mathrm{min}$, with doses increasing at a rate limited by side effects (local site pain, flushing, headache). The optimal dose varies between individual patients, ranging in the majority between 20 and $80 \mathrm{ng} /$ $\mathrm{kg} / \mathrm{min}$ (figure 2).

\section{CONCLUSION}

This overview emphasizes the complexity of PH and PAH or group $1 \mathrm{PH}$. We encourage early referral to tertiary care $\mathrm{PH}$ centers to coordinate management between cardiologists, pulmonologist and internists. Despite advances in therapies for $\mathrm{PAH}$, individualization of care is essential to choosing between various options. Sequential dual or tertiary therapy for patients with $\mathrm{PAH}$ who fail monotherapy is recommended by the ESC/ERS. We suggest that upfront dual or even tertiary therapy in selected patients with moderate-risk to high-risk features might be helpful in improving prognosis in these subsets of patients. Subsequent studies addressing this question will be needed.

Funding The authors have not declared a specific grant for this research from any funding agency in the public, commercial or not-for-profit sectors.

Competing interests None declared.

Patient consent for publication Not required.

Provenance and peer review Commissioned; externally peer reviewed.

Author note Pulmonary arterial hypertension (PAH) carries a poor prognosis if not promptly diagnosed and appropriately treated. The development and approval of 14 medications over the last several decades have led to a rapidly evolving approach to therapy, and have necessitated periodic updating of evidence-based treatment guidelines.

Open access This is an open access article distributed in accordance with the Creative Commons Attribution Non Commercial (CC BY-NC 4.0) license, which permits others to distribute, remix, adapt, build upon this work noncommercially, and license their derivative works on different terms, provided the original work is properly cited, an indication of whether changes were made, and the use is non-commercial. See: http://creativecommons.org/ licenses/by-nc/4.0/.

\section{ORCID iD}

Theo Trandafirescu http://orcid.org/0000-0002-5953-9516

\section{REFERENCES}

1 Simonneau G, Montani D, Celermajer DS, et al. Haemodynamic definitions and updated clinical classification of pulmonary hypertension. Eur Respir J 2019;53:1801913

2 Galiè N, Humbert M, Vachiery J-L, et al. 2015 ESC/ERS guidelines for the diagnosis and treatment of pulmonary hypertension: the joint Task force for the diagnosis and treatment of pulmonary hypertension of the European Society of cardiology (ESC) and the European respiratory Society (ERS): endorsed by: association for European paediatric and congenital cardiology (AEPC), International Society for heart and lung transplantation (ISHLT). Eur Respir J 2015;46:903-75.

3 Kovacs G, Berghold A, Scheidl S, et al. Pulmonary arterial pressure during rest and exercise in healthy subjects: a systematic review. Eur Respi J 2009;34:888-94.

4 Bossone $E$, Paciocco $G$, larussi $D$, et al. The prognostic role of the ECG in primary pulmonary hypertension. Chest 2002;121:513-8.

5 Olsson KM, Nickel NP, Tongers J, et al. Atrial flutter and fibrillation in patients with pulmonary hypertension. Int J Cardio/ 2013;167:2300-5.

6 Frost A, Badesch D, Gibbs JSR, et al. Diagnosis of pulmonary hypertension. Eur Respir J 2019;53:1801904.

7 Jacobs W, Konings TC, Heymans MW, et al. Noninvasive identification of left-sided heart failure in a population suspected of pulmonary arterial hypertension. Eur Respir J 2015;46:422-30.

8 Fisher MR, Forfia PR, Chamera E, et al. Accuracy of Doppler echocardiography in the hemodynamic assessment of pulmonary hypertension. Am J Respir Crit Care Med 2009;179:615-21.

9 Rich JD, Shah SJ, Swamy RS, et al. Inaccuracy of Doppler echocardiographic estimates of pulmonary artery pressures in patients with pulmonary hypertension: implications for clinical practice. Chest 2011;139:988-93.

10 Lewis R, Cogliano M, Johns CS, et al. Cardiac MRI: identifying thresholds to predict mortality in pulmonary arterial hypertension. B27. Heartbreaker: heart failure and pulmonary hypertension. Am Thorac Soc 2019;99:A2809.

11 Benza RL, Miller DP, Foreman AJ, et al. Prognostic implications of serial risk score assessments in patients with pulmonary arterial hypertension: a Registry to evaluate early and long-term pulmonary arterial hypertension disease management (reveal) analysis. J Heart Lung Transplant 2015;34:356-61.

12 Benza RL, Miller DP, Barst RJ, et al. An evaluation of long-term survival from time of diagnosis in pulmonary arterial hypertension from the reveal registry. Chest 2012;142:448-56.

13 Hoeper MM, Ghofrani H, Grunig E, et al. Pulmonary hypertension. Deutsches Ärzteblatt International 2017;114.5:73.

14 Raymond RJ, Hinderliter AL, Willis PW, et al. Echocardiographic predictors of adverse outcomes in primary pulmonary hypertension. J Am Coll Cardiol 2002;39:1214-9.

15 Barst RJ. Pulmonary hypertension: past, present and future. Ann Thorac Med 2008;3:1-4.

16 Humbert M. Pulmonary arterial hypertension and chronic thromboembolic pulmonary hypertension: pathophysiology. Eur Respir Rev 2010;19:59-63.

17 Norman Shumway. BMJ 2006;332:553.

18 Preston IR, Roberts KE, Miller DP, et al. Effect of warfarin treatment on survival of patients with pulmonary arterial hypertension $(\mathrm{PAH})$ in the registry to evaluate early and long-term PAH disease management (reveal). Circulation 2015; 132:2403-11.

19 Olsson KM, Delcroix M, Ghofrani HA, et al. Anticoagulation and survival in pulmonary arterial hypertension: results from the comparative, prospective registry of newly initiated therapies for pulmonary hypertension (COMPERA) Circulation 2014;129:57-65.

20 Barst RJ, Rubin LJ, Long WA, et al. A comparison of continuous intravenous epoprostenol (prostacyclin) with conventional therapy for primary pulmonary hypertension. N Engl J Med 1996:334:296-301.

21 Sitbon 0 , Humbert $M$, Jaïs $X$, et al. Long-term response to calcium channel blockers in idiopathic pulmonary arterial hypertension. Circulation 2005;111:3105-11. 